\title{
Long-term survival, valve durability, and reoperation for 4 aortic root procedures combined with ascending aorta replacement
}

\author{
Lars G. Svensson, MD, PhD, ${ }^{\text {a,b }}$ Saila T. Pillai, MD, MPH, ${ }^{a}$ Jeevanantham Rajeswaran, PhD, \\ Milind Y. Desai, MD, ${ }^{\mathrm{b}, \mathrm{d}}$ Brian Griffin, MD, ${ }^{\mathrm{b}, \mathrm{d}}$ Richard Grimm, DO, ${ }^{\mathrm{b}, \mathrm{d}}$ Donald F. Hammer, MD, ${ }^{\mathrm{b}, \mathrm{d}}$ \\ Maran Thamilarasan, MD, ${ }^{\mathrm{b}, \mathrm{d}}$ Eric E. Roselli, MD, ${ }^{\mathrm{a}, \mathrm{b}}$ Gösta B. Pettersson, MD, PhD,,${ }^{\mathrm{a}, \mathrm{b}}$ \\ A. Marc Gillinov, MD, ${ }^{\mathrm{a}, \mathrm{b}}$ Jose L. Navia, MD, ${ }^{\mathrm{a}, \mathrm{b}}$ Nicholas G. Smedira, MD, ${ }^{\mathrm{a}, \mathrm{b}}$ Joseph F. Sabik III, MD, ${ }^{\mathrm{a}, \mathrm{b}}$ \\ Bruce W. Lytle, MD, ${ }^{a, b}$ and Eugene H. Blackstone, $\mathrm{MD}^{\mathrm{a}, \mathrm{b}, \mathrm{c}}$
}

\begin{abstract}
Objective: To evaluate long-term results of aortic root procedures combined with ascending aorta replacement for aneurysms, using 4 surgical strategies.

Methods: From January 1995 to January 2011, 957 patients underwent 1 of 4 aortic root procedures: valve preservation (remodeling or modified reimplantation, $\mathrm{n}=261)$; composite biologic graft $(\mathrm{n}=297)$; composite mechanical graft $(\mathrm{n}=156)$; or allograft root $(\mathrm{n}=243)$.
\end{abstract}

Results: Seven deaths occurred $(0.73 \%)$, none after valve-preserving procedures, and 13 strokes $(1.4 \%)$. Composite grafts exhibited higher gradients than allografts or valve preservation, but the latter 2 exhibited more aortic regurgitation (2.7\% biologic and $0 \%$ mechanical composite grafts vs $24 \%$ valve-preserving and $19 \%$ allografts at 10 years). Within 2 to 5 years, valve preservation exhibited the least left ventricular hypertrophy, allograft replacement the greatest; however, valve preservation had the highest early risk of reoperation, allograft replacement the lowest. Patients receiving allografts had the highest risk of late reoperation $(P<.05)$, and those receiving composite mechanical grafts and valve preservation had the lowest. Composite bioprosthesis patients had the highest risk of late death ( $57 \%$ at 15 years vs $14 \%-26 \%$ for the remaining procedures, $P<.0001$ ), because they were substantially older and had more comorbidities $(P<.0001)$.

Conclusions: These 4 aortic root procedures, combined with ascending aorta replacement, provide excellent survival and good durability. Valve-preserving and allograft procedures have the lowest gradients and best ventricular remodeling, but they have more late regurgitation, and likely, less risk of valve-related complications, such as bleeding, hemorrhage, and endocarditis. Despite the early risk of reoperation, we recommend valve-preserving procedures for young patients when possible. Composite bioprostheses are preferable for the elderly. (J Thorac Cardiovasc Surg 2016;151:764-74)

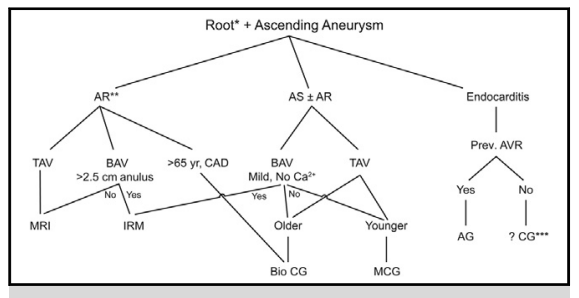

Current Cleveland Clinic treatment algorithm for root and ascending aortic aneurysm.

\section{Central Message}

Aortic valve-preserving root procedures are recommended for young patients; composite bioprostheses are reasonable for the elderly.

\section{Perspective}

Four aortic root procedures combined with ascending aorta replacement-valve preservation, mechanical or biologic composite grafts, and allografts-provide excellent survival and good durability. Valve-preserving and allograft procedures have the lowest gradients, but more late regurgitation. We recommend valvepreserving procedures for young patients; composite bioprostheses are reasonable for the elderly.

See Editorial Commentary page 775 .
In the past, a Bentall operation, which incorporates an artificial aortic valve within an ascending aorta tube graft, was the standard treatment for various combined aortic root and

From the Departments of ${ }^{\mathrm{a}}$ Thoracic and Cardiovascular Surgery and ${ }^{\mathrm{d}} \mathrm{Cardiovascular}$ Medicine, and ${ }^{\mathrm{b}}$ Aorta Center, Heart and Vascular Institute, Cleveland Clinic; and ${ }^{\mathrm{c}}$ Department of Quantitative Health Sciences, Research Institute, Cleveland Clinic, Cleveland, Ohio.

This study was funded in part by the Gus P. Karos Family Registry Fund, the David Whitmire Hearst Jr Foundation, the John and Rosemary Brown Endowed Chair in Cardiovascular Medicine (held by Dr Griffin), the Peter and Elizabeth C. Tower and Family Endowed Chair in Cardiothoracic Research (held by Dr Pettersson), the Judith Dion Pyle Endowed Chair in Heart Valve Research (held by Dr Gillinov), the Sheikh Hamdan bin Rashid Al Maktoum Distinguished Chair in Thoracic and Cardiovascular Surgery (held by Dr Sabik), and the Kenneth Gee and Paula Shaw, $\mathrm{PhD}$, Chair in Heart Research (held by Dr Blackstone). These individuals and funding organizations played no role in the collection of data or analysis and interpre- ascending aorta pathologies. ${ }^{1}$ Initially, the valve was mechanical ("composite grafts"), but bioprostheses were eventually introduced, ${ }^{2}$ as were allografts, ${ }^{3}$ for combined tation of the data, and had no right to approve or disapprove publication of the finished article.

Read at the 95th Annual Meeting of The American Association for Thoracic Surgery, Seattle, Washington, April 25-29, 2015.

Received for publication April 23, 2015; revisions received Oct 23, 2015; accepted for publication Oct 27, 2015; available ahead of print Jan 8, 2016.

Address for reprints: Lars G. Svensson, MD, PhD, Heart and Vascular Institute, Cleveland Clinic, 9500 Euclid Ave/Desk J4-1, Cleveland, OH 44915 (E-mail: svenss1@ccf.org).

$0022-5223 / \$ 36.00$

Copyright (c) 2016 by The American Association for Thoracic Surgery

http://dx.doi.org/10.1016/j.jtcvs.2015.10.113 
Scanning this QR code will take you to the article title page. To view the AATS 2015 Webcast, see the URL at the end of the article.

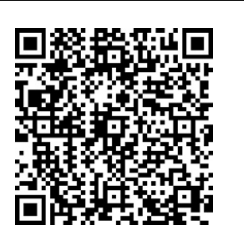

aortic root and ascending aorta replacement. Over the past 25 years, David and colleagues ${ }^{4}$ have championed a variety of valve-preserving techniques. It remains uncertain, however, which of these techniques - older or newer-is the right one for the right patient at the right time. ${ }^{5-7}$

In a previous comparison of appropriate root procedures (modified reimplantation for tricuspid aortic valves and remodeling for bicuspid ones) versus a biologic composite valve, we showed that modified reimplantation exhibited superior durability after 9 to 10 years, compared with remodeling, which showed better durability after 10 to 12 years. ${ }^{5}$ Furthermore, bicuspid valve repair-40\% combined with aortic surgery-carried a $0.47 \%$ risk of hospital death and a $0.25 \%$ risk of stroke, and long-term durability improved over time with newer techniques, such as higher commissure implantation. ${ }^{8}$ However, how reparative procedures compare with mechanical and biologic graft root replacement alternatives in the long term remains unclear. ${ }^{6,9}$

The present study goes beyond our previous reports, to examine our experience over the past 20 years with aortic root procedures combined with ascending aorta replacement. All of the patients in the study were managed with (1) valve preservation (remodeling or modified reimplantation); (2) biologic valve composite grafts; (3) mechanical valve composite grafts; or (4) allograft root and ascending aorta replacement with coronary reimplantation. On the basis of long-term outcomes and surveillance in an era that favors reparative techniques, do mechanical and biologic composite grafts and allografts still have a place? If so, in what kind of patient, at what time?

\section{METHODS \\ Patients}

From January 1995 to January 2011, 957 patients underwent 1 of 4 aortic root procedures for aneurysms of the root and ascending aorta: (1) valve preservation ( $\mathrm{n}=261$; remodeling $[\mathrm{n}=56]$ or reimplantation $[\mathrm{n}=205])$; (2) composite biologic graft $(\mathrm{n}=297)$; (3) composite mechanical graft ( $\mathrm{n}=156)$; or (4) allograft root $(\mathrm{n}=243)$. Patients who underwent emergency surgery, had endocarditis or acute aortic dissection, or did not have an ascending aorta replacement were excluded.

\section{Operative Techniques}

The operative techniques have been described before for the root part of the procedure, including a L.G.S.-modified valve reimplantation technique using pledgets, sizing to body surface area, and Hegar's dilators ${ }^{5,10}$; an inclusion type of remodeling of the root $^{6}$; composite mechanical valve implantation, including with a tube graft to the left main coronary artery (which we now use primarily for patients with acute dissection or who have undergone reoperation ${ }^{11,12}$ ); standard techniques for biologic implants with coronary buttons; and allograft root implantation by the inclusion or button technique. In 234 patients (24\%), circulatory arrest was used for concomitant aortic arch replacement (Table 1).

\section{Data}

Data were collected prospectively and entered into our Cardiovascular Information Registry. Use of these data for research was approved by the Cleveland Clinic Institutional Review Board, with requirements for patient consent waived.

\section{Endpoints}

Study endpoints were (1) in-hospital postoperative morbidity and mortality; (2) time-related aortic valve function (assessed by gradients and regurgitation on longitudinal echocardiograms); (3) left ventricular reverse remodeling, assessed by left ventricular mass on longitudinal echocardiograms; (4) aortic valve and aorta-related reoperations; and (5) short- and long-term mortality.

Longitudinal echocardiographic data for aortic valve function and left ventricular reverse remodeling obtained at follow-up were extracted from our echocardiogram database to ascertain valve function. However, surveillance echocardiograms were available only in patients who were followed at Cleveland Clinic. Previously, we have shown that these patients constitute a representative sample, one not confounded by return of patients for aortic problems. ${ }^{13}$ Few statistically significant differences were found between patients surveilled or not at Cleveland Clinic (data not shown).

A total of 1626 echocardiograms, performed on 718 patients (75\%), were available for analysis in the postoperative period (Figure E1). Time-related survival and aortic-related reoperations were obtained from yearly follow-up questionnaires (with phone follow-up if questionnaires were not returned). Follow-up was available for 943 patients $(98 \%)$. The median follow-up time was 5.3 years (mean, $5.6 \pm 4.6$ years), with 5351 patient-years of data available for analysis; $25 \%$ of patients were followed for $>9$ years, and $5 \%$ for $>15$ years.

\section{Data Analysis}

The following outline of our data analysis is presented in detail in Appendix E1. To reduce bias in comparing outcomes among groups, 4 propensity scores were generated for each patient and forced into models of outcome. The temporal patterns of follow-up echocardiographic measures were estimated using longitudinal data analysis, with riskadjusted comparisons made by including propensity scores in the models. Risks of reoperation and death were estimated by the Kaplan-Meier method, and a nonproportional hazards model was used to identify risk-adjusted mortality differences.

\section{Presentation}

Continuous variables are summarized as mean \pm standard deviation, or as equivalent 15 th, 50 th (median), and 85 th percentiles when the distribution of values was skewed. Categoric data are summarized as frequencies and percentages. Uncertainty is expressed by confidence limits equivalent to \pm 1 standard error $(68 \%)$. Comparison of groups was done with the Kruskal-Wallis nonparametric test for continuous variables and the $\chi^{2}$ test for categoric data.

\section{RESULTS}

\section{Patient Characteristics and Procedural Details}

Patients in the valve-preserving and mechanical composite valve groups were the youngest, and those receiving a biologic composite graft were the oldest (Table E1). Patients in the valve-preserving group also 
TABLE 1. Procedural characteristics stratified by aortic root procedure

\begin{tabular}{|c|c|c|c|c|c|c|c|c|c|}
\hline \multirow[b]{3}{*}{ Characteristic } & \multirow{2}{*}{\multicolumn{2}{|c|}{ Valve preservation $(n=261)$}} & \multicolumn{4}{|c|}{ Composite graft } & \multirow{2}{*}{\multicolumn{2}{|c|}{ Allograft $(n=243)$}} & \multirow[b]{3}{*}{$\begin{array}{c}P \\
\text { value } \\
\end{array}$} \\
\hline & & & \multicolumn{2}{|c|}{ Biologic $(n=297)$} & \multicolumn{2}{|c|}{ Mechanical $(n=156)$} & & & \\
\hline & $\mathbf{n}^{*}$ & $\begin{array}{l}\text { No. }(\%) \text { or } \\
\text { mean } \pm \text { SD }\end{array}$ & $\mathbf{n} *$ & $\begin{array}{l}\text { No. }(\%) \text { or } \\
\text { mean } \pm \text { SD }\end{array}$ & $\mathbf{n}^{*}$ & $\begin{array}{l}\text { No. }(\%) \text { or } \\
\text { mean } \pm \text { SD }\end{array}$ & n* & $\begin{array}{l}\text { No. }(\%) \text { or } \\
\text { mean } \pm \text { SD }\end{array}$ & \\
\hline \multicolumn{10}{|l|}{ Approach } \\
\hline Full sternotomy & 181 & $174(96)$ & 178 & $159(89)$ & 113 & $105(93)$ & 174 & $135(78)$ & $<.0001$ \\
\hline Partial upper J-incision & 181 & $5(2.8)$ & 178 & $18(10)$ & 113 & $8(7.1)$ & 174 & $36(21)$ & $<.0001$ \\
\hline $\begin{array}{l}\text { Partial converted to full } \\
\text { sternotomy }\end{array}$ & 181 & $2(1.1)$ & 178 & $1(0.56)$ & 113 & $0(0)$ & 174 & $3(1.7)$ & .5 \\
\hline \multicolumn{10}{|l|}{ Support } \\
\hline Circulatory arrest & 261 & $41(16)$ & 297 & $89(30)$ & 156 & $42(27)$ & 243 & $62(26)$ & .001 \\
\hline Circulatory arrest time (min) & 41 & $17 \pm 9.8$ & 89 & $16 \pm 8.6$ & 42 & $14 \pm 5.0$ & 62 & $16 \pm 6.4$ & .2 \\
\hline Aortic clamp time (min) & 261 & $109 \pm 28$ & 297 & $99 \pm 34$ & 156 & $95 \pm 33$ & 243 & $98 \pm 31$ & $<.0001$ \\
\hline CPB time (min) & 261 & $134 \pm 37$ & 297 & $123 \pm 45$ & 156 & $120 \pm 43$ & 243 & $120 \pm 41$ & $<.0001$ \\
\hline \multicolumn{10}{|l|}{ Concomitant procedures } \\
\hline Mitral valve surgery & 261 & $19(7.3)$ & 297 & $20(6.7)$ & 156 & $11(7.1)$ & 243 & $12(4.9)$ & .7 \\
\hline Repair & 261 & $19(7.3)$ & 297 & $16(5.4)$ & 156 & $6(3.8)$ & 243 & $10(4.1)$ & .3 \\
\hline Replacement & 261 & $0(0)$ & 297 & $4(1.3)$ & 156 & $5(3.2)$ & 243 & $2(0.82)$ & .03 \\
\hline Tricuspid valve repair & 261 & $2(0.77)$ & 297 & $7(2.4)$ & 156 & $1(0.64)$ & 243 & $2(0.82)$ & .2 \\
\hline Coronary artery bypass grafting & 261 & $23(8.8)$ & 297 & $99(33)$ & 156 & $22(14)$ & 243 & $41(17)$ & $<.0001$ \\
\hline Atrial fibrillation procedure & 261 & $7(2.7)$ & 297 & $23(7.7)$ & 156 & $3(1.9)$ & 243 & $10(4.1)$ & .008 \\
\hline
\end{tabular}

$S D$, Standard deviation; $C P B$, cardiopulmonary bypass. *Patients with data available.

exhibited the least aortic valve regurgitation, stenosis, and left ventricular remodeling and dysfunction preoperatively; large aneurysms; and a lower likelihood of having a bicuspid valve, valve calcification, or heart failure. By contrast, patients in the biologic composite graft group were older and more symptomatic, and had greater ventricular hypertrophy than those in the valve-preserving group. The mechanical composite and allograft groups had greater ventricular hypertrophy.

Patients who received a mechanical composite had the largest label size prosthesis: $61 \%$ had size 22 or $27 \mathrm{~mm}$, with $19 \%$ larger than this; $66 \%$ of biologic composite grafts contained a bioprosthesis label size of 25 or $27 \mathrm{~mm}$, with only $4.7 \%$ larger than this. Most allografts $(57 \%$ ) were size 21 or $22 \mathrm{~mm}$ (these are internally sized) (Table E2).

These differences, differences in indication for operation (including need to address severe aortic regurgitation with modest aortic dilatation as well as modest aortic valve pathology in patients with importantly enlarged roots), and differences over time in the way the aortic root was measured meant that average root dimension was at times not severely enlarged and the aortic regurgitation was at times not severe. For example, the primary indication may have been aortic root size, and yet the ascending aorta may not have been severely enlarged, and vice versa. Hence, the average measured sizes may seem artificially small. In addition, some patients require aortic root and ascending aortic procedures before undergoing aorta operations that are distal to the subclavian artery, and their root and aorta may not have been as enlarged.
Over the course of the study, use of valve-preserving and biologic composite graft procedures increased; mechanical composite graft procedures increased in the early 2000s, then decreased; and allograft root replacement peaked in about 2000, then declined to a low level (Figure 1). Allograft roots were the most likely to be inserted during a less-invasive procedure; circulatory arrest was least used during valve-preserving procedures; and concomitant coronary artery bypass grafting was most likely to be performed in patients who received composite biologic grafts (Table 1). Although most of these coronary artery bypass grafting procedures were used for coronary artery disease (144 of 178 patients [81\%] with coronary stenosis $\geq 50 \%$ ), they were used in 5 patients in the valve-sparing group ( 3 with balloon perfusion catheter-associated coronary dissection), and in 36 in the remaining groups, particularly in elderly patients who received bioprosthetic composite grafts $(\mathrm{n}=23)$ for coronary ostial technical reasons, which occurred in 5 patients who had mechanical composites and 8 who had allografts.

\section{In-Hospital Outcomes}

Atrial fibrillation $(P<.0001)$ and reoperation for bleeding $(P=.06)$ tended to be more common after composite biologic procedures in these older patients (Table 2). Patients who received allografts had the shortest intensive care unit stay, but those in the valve-preserving group had the shortest overall postoperative hospital stay. Risks of stroke $(\mathrm{n}=13 ; 1.4 \%)$ and death $(\mathrm{n}=7 ; 0.73 \%)$ were similar among groups. 


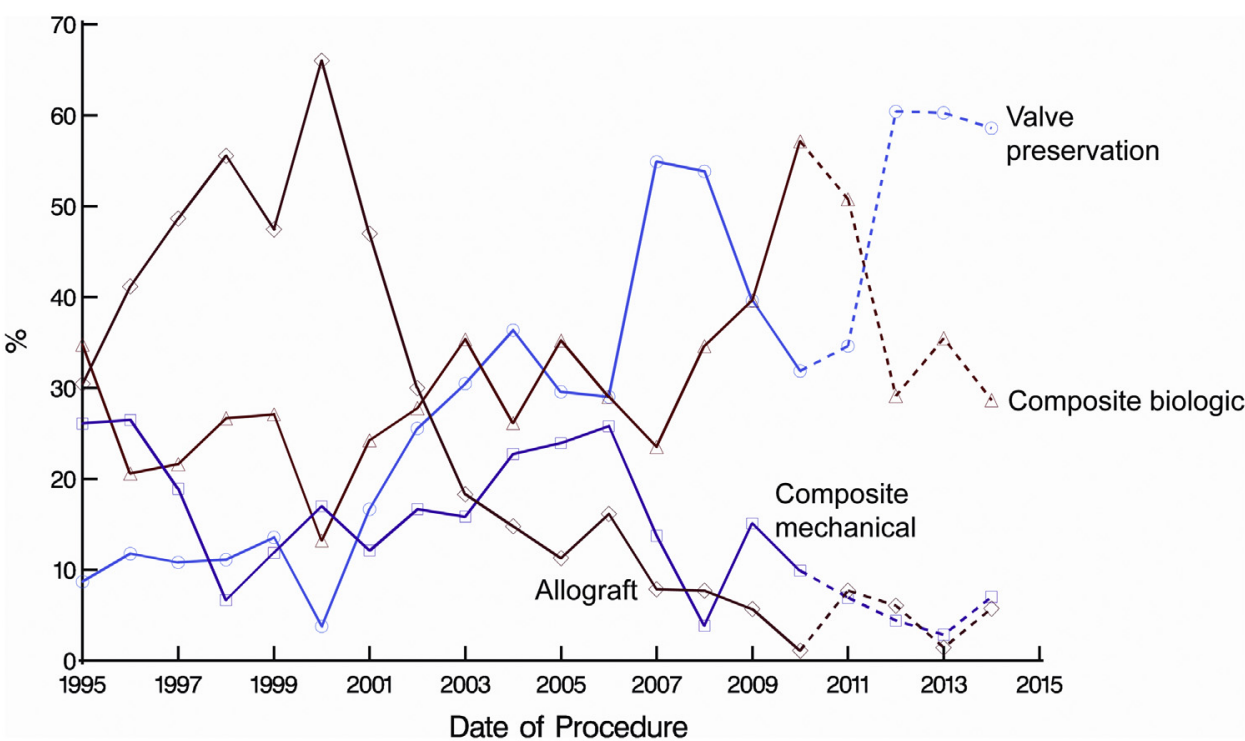

FIGURE 1. Yearly volume of aortic root procedure use, all combined with ascending aorta replacement. Dashed lines indicate trends for the 4 years since the end of the study period for this article. They demonstrate that biologic composite grafts comprise approximately $30 \%$ of current procedures, valve-preserving procedures about $60 \%$, and mechanical composite grafts and allografts approximately $5 \%$ each.

\section{Valve Function}

Both valve-preserving and allograft procedures had lower early mean gradients than did composite grafts with either a biologic or mechanical valve $(P<.0001$; Figure $2, A)$. Both mechanical and bioprosthetic composite grafts were predominantly sizes 23,25 , or $27 \mathrm{~mm}$, but prosthesis size was associated with higher postoperative gradients $(P<.0001$ and $P=.02$, respectively), as was true of allografts $(P=.03)$, for which the internal diameter was predominantly 21 or $22 \mathrm{~mm}$ (Table E2). Aortic valve regurgitation increased over time (Figure 2, B), particularly for valve-preserving and allograft procedures, although it was similar in these 2 groups $(24 \%$ and $19 \%$ at 10 years, respectively; $P=.2$; risk-adjusted $P=.08$ ). Severe regurgitation after composite graft replacement with a mechanical valve occurred in only 1 patient, but it reached $2.7 \%$ at 10 years with a bioprosthesis. The mode of failure of the biologic composite grafts was predominantly aortic valve stenosis, whereas for valvepreserving and allograft procedures, the mode of failure was predominantly regurgitation.

TABLE 2. Hospital course and adverse events stratified by aortic root procedure

\begin{tabular}{|c|c|c|c|c|c|c|c|c|c|}
\hline \multirow[b]{3}{*}{ Event } & \multirow{2}{*}{\multicolumn{2}{|c|}{$\begin{array}{c}\text { Valve preservation } \\
(\mathrm{n}=\mathbf{2 6 1}) \\
\end{array}$}} & \multicolumn{4}{|c|}{ Composite graft } & \multirow{2}{*}{\multicolumn{2}{|c|}{ Allograft $(n=243)$}} & \multirow[b]{3}{*}{$\begin{array}{c}P \\
\text { value } \\
\end{array}$} \\
\hline & & & \multicolumn{2}{|c|}{$\begin{array}{c}\text { Biologic } \\
(n=297)\end{array}$} & \multicolumn{2}{|c|}{$\begin{array}{l}\text { Mechanical } \\
(\mathbf{n}=156)\end{array}$} & & & \\
\hline & $\mathbf{n}^{*}$ & $\begin{array}{l}\text { No. }(\%) \text { or } \\
\text { mean } \pm \text { SD }\end{array}$ & $\mathbf{n}^{*}$ & $\begin{array}{l}\text { No. }(\%) \text { or } \\
\text { mean } \pm \text { SD }\end{array}$ & $\mathbf{n}^{*}$ & $\begin{array}{l}\text { No. }(\%) \text { or } \\
\text { mean } \pm \text { SD }\end{array}$ & $\mathbf{n}^{*}$ & $\begin{array}{l}\text { No. }(\%) \text { or } \\
\text { mean } \pm \text { SD }\end{array}$ & \\
\hline Hospital death & 261 & $0(0)$ & 297 & $4(1.3)$ & 156 & $1(0.64)$ & 243 & $2(0.82)$ & .3 \\
\hline Reoperation for valve dysfunction & 255 & $4(1.6)$ & 282 & $0(0)$ & 141 & $0(0)$ & 222 & $1(0.45)$ & .07 \\
\hline Atrial fibrillation & 261 & $65(25)$ & 297 & $132(44)$ & 156 & $43(28)$ & 243 & $61(25)$ & $<.0001$ \\
\hline Prolonged ventilation $(>24 \mathrm{~h})$ & 225 & $13(5.8)$ & 222 & $18(8.1)$ & 107 & $8(7.5)$ & 85 & $6(7.1)$ & .8 \\
\hline Reoperation for bleeding or tamponade & 261 & $7(2.7)$ & 297 & $21(7.1)$ & 156 & $5(3.2)$ & 243 & $10(4.1)$ & .06 \\
\hline Permanent stroke & 261 & $3(1.1)$ & 297 & $4(1.3)$ & 156 & $1(0.64)$ & 243 & $5(2.1)$ & .7 \\
\hline Perioperative myocardial infarction & 261 & $6(2.3)$ & 297 & $0(0)$ & 156 & $0(0)$ & 243 & $4(1.6)$ & .02 \\
\hline Intra-aortic balloon pump & 261 & $5(1.9)$ & 297 & $5(1.7)$ & 156 & $0(0)$ & 243 & $0(0)$ & .06 \\
\hline Insertion of ventricular assist device & 261 & $2(0.77)$ & 297 & $2(0.67)$ & 156 & $0(0)$ & 243 & $0(0)$ & .4 \\
\hline Deep sternal wound infection & 261 & $0(0)$ & 297 & $1(0.34)$ & 156 & $0(0)$ & 243 & $2(0.82)$ & .3 \\
\hline Renal failure requiring dialysis & 261 & $0(0)$ & 297 & $1(0.34)$ & 156 & $0(0)$ & 243 & $1(0.41)$ & .7 \\
\hline \multicolumn{10}{|l|}{ Length of stay $\dagger$} \\
\hline Intensive care unit (h) & 261 & $23 / 28 / 70$ & 297 & $23 / 29 / 80$ & 156 & $22 / 28 / 72$ & 243 & $24 / 24 / 48$ & $<.0001$ \\
\hline Postoperative (d) & 261 & $5.1 / 6.2 / 10$ & 297 & $5.1 / 6.2 / 12$ & 156 & $5.2 / 7.1 / 10$ & 243 & 4.8/5.9/9.0 & $<.0001$ \\
\hline Hospital (d) & 261 & $5.3 / 6.3 / 11$ & 297 & $5.3 / 7.2 / 15$ & 156 & $6.1 / 8.0 / 12$ & 243 & $5.2 / 6.3 / 11$ & $<.0001$ \\
\hline
\end{tabular}

$S D$, Standard deviation. *Patients with data available. $\nmid 15$ th $/ 50$ th/85th percentiles. 

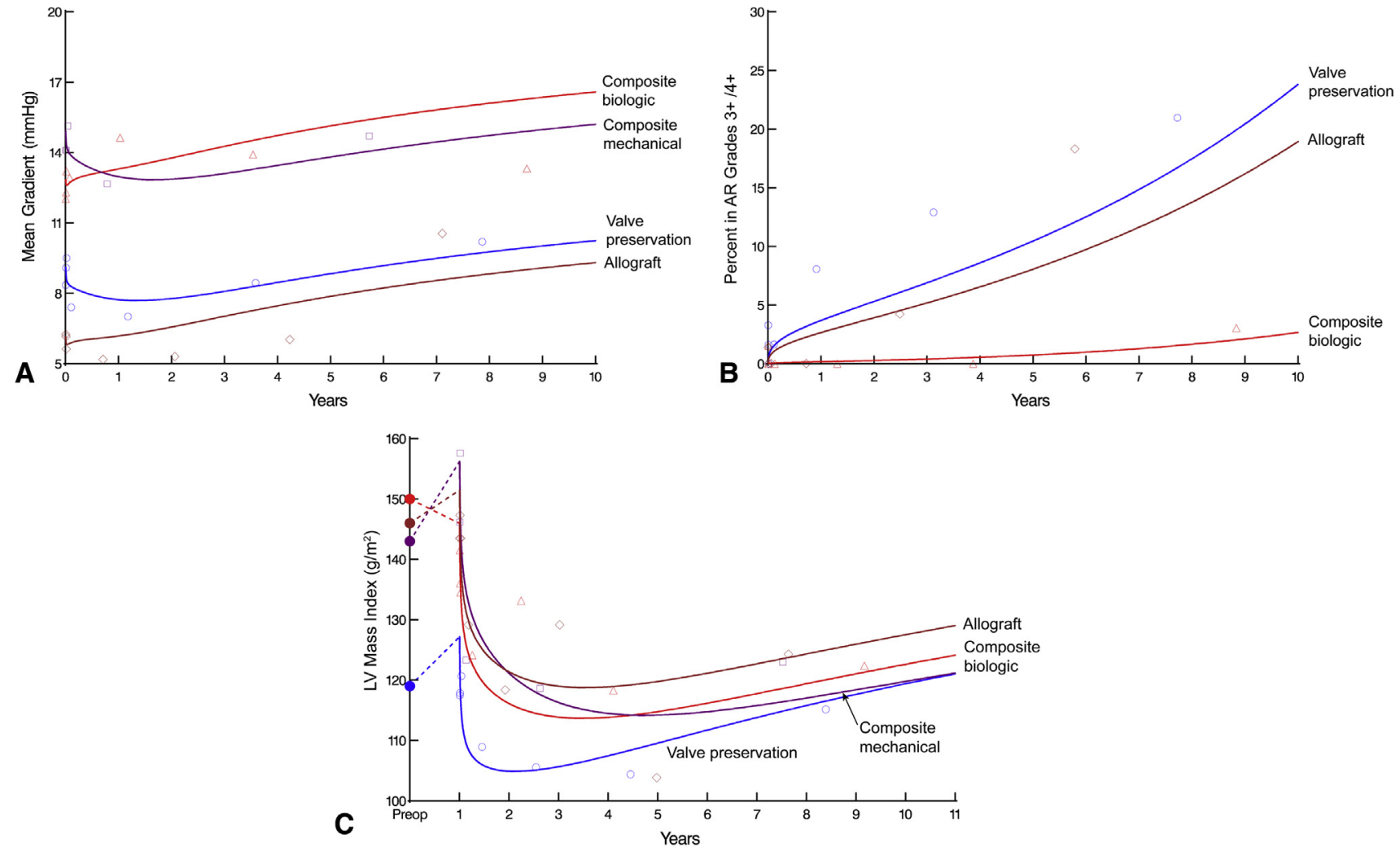

FIGURE 2. Temporal trends of longitudinal measures after 4 aortic root procedures for aneurysms. Solid lines represent unadjusted estimates of temporal trend, and symbols represent data grouped (without regard to repeated measurements) within a timeframe to provide a crude verification of model fit. A, Mean aortic valve gradient; (B) Grade 3+/4 + postoperative AR. Only 1 mechanical composite valve developed severe regurgitation. C, LV mass index. $A R$, Aortic valve regurgitation; $L V$, left ventricular. Red triangles $=$ composite graft replacement with biologic valve; purple squares $=$ composite graft replacement with mechanical valve; blue circles $=$ valve preservation; and brown diamonds = allograft root and ascending aorta replacement with coronary reimplantation.

\section{Left Heart Reverse Remodeling}

Left ventricular reverse remodeling occurred differently among these 4 procedure groups. The pattern of postoperative left ventricular mass index was to decrease during the first 3 years, and increase thereafter. The valve-preservation group had the lowest left ventricular mass index at 3 years, compared with the other groups $(P=.001$; Figure 2, $C)$. However, the preoperative left ventricular mass index was lowest in this group. Thus, the proportionate decrease in the index in the valve-preservation group was less than that in other groups.

\section{Reoperation}

In all, 74 aorta or aortic valve-related reoperations took place, in 68 patients (Table 3). Hospital mortality was $1.5 \%$ for the first reoperation and $0 \%$ for the second. The probability of reoperation varied by strategy (Figure 3,A). Early reoperation was more common after valve preservation and biologic composite graft procedures (Table 4; Table E3). Allograft root replacement and biologic composite grafts had the highest late risk of reoperation, and mechanical composite grafts and valve preservation had the lowest, suggesting good outcomes for valve preservation once the initial early failures were addressed.

In a subgroup analysis of the risk of reoperation after valve preservation using root remodeling for bicuspid valves versus reimplantation for tricuspid valves (Figure 3, B), reimplantation for tricuspid aortic valves had lower risk $\left(P_{\text {log-rank }}=.02\right)$ and remodeling an intermediate risk $\left(P_{\text {log-rank }}=.11\right)$.

\section{Death}

Patients who underwent composite graft replacement with a biologic valve had the worst survival $(P<.0001$; Figure 4), which was attributable to differences in patient characteristics rather than operative strategy (propensityscore risk-adjusted $P>.2$ ).

\section{DISCUSSION}

\section{Principal Findings}

For patients who have various aortic root pathologies and ascending aortic aneurysm, all of whom would have been considered for a Bentall-type procedure in the past, we see in this large, single-institution series a nearly complete 
TABLE 3. Reoperation details

\begin{tabular}{|c|c|c|c|c|}
\hline \multirow[b]{2}{*}{ Reoperation } & \multirow{2}{*}{$\begin{array}{c}\text { Valve } \\
\text { preservation }\end{array}$} & \multicolumn{2}{|c|}{ Composite graft } & \multirow[b]{2}{*}{ Allograft } \\
\hline & & Biologic & Mechanical & \\
\hline AVR & 7 & 2 & 0 & 15 \\
\hline $\begin{array}{l}\text { AVR + proximal } \\
\text { aorta replacement }\end{array}$ & 6 & 7 & 3 & 16 \\
\hline $\begin{array}{r}\text { Proximal aorta } \\
\text { replacement }\end{array}$ & 0 & 0 & 1 & 1 \\
\hline $\begin{array}{l}\text { Proximal and } \\
\text { descending aorta } \\
\text { replacement }\end{array}$ & 4 & 2 & 0 & 1 \\
\hline $\begin{array}{l}\text { Descending aorta } \\
\text { replacement }\end{array}$ & 5 & 2 & 2 & 0 \\
\hline
\end{tabular}

shift. Changes include movement away from mechanical composite grafts to valve-preserving procedures in younger patients; emergence of biologic composite grafts for older patients and those who believe they will be candidates for valve-in-valve transcatheter valve replacement in the future; and a near disappearance of allograft root and ascending aorta replacement.

However, mean aortic gradients were elevated in composite grafts, particularly those of small size, above that of either valve-preserving or allograft procedures, although the latter 2 developed regurgitation over time. Risk of regurgitation was greatest for allografts and least for composite mechanical devices. Risk of late death was related to age and comorbidities, not to strategy for managing the aortic root. All these procedures, either primary or reoperation, were performed with low hospital mortality and low risk of stroke.

\section{Findings in Context}

This study shows excellent early results after aortic root surgery combined with ascending aorta replacement, with a $0.73 \%$ in-hospital mortality, and no in-hospital deaths after valve-preservation procedures. Other recent reports, including our own, have demonstrated mortality ranging from $0.5 \%$ to $3.4 \%$ for valve preservation. ${ }^{4,5,14-17}$ Valve preservation was associated with lower postoperative gradients, resulting in left ventricular reverse remodeling to nearly the upper limit of normal, although this group of patients had the least remodeling preoperatively. Risk of death was also lower over time with valve preservation than with biologic composite grafts, but similar compared with mechanical composite grafts or allograft roots. However, any differences in survival were attributable to differences in patient demographics, particularly age, and to the prevalence of comorbidities.

The downside of valve preservation was an early risk of reoperation, although this risk was specifically related to remodeling of bicuspid valves, whereas reimplantation of tricuspid aortic valves provided excellent results. However, this comparison is likely one of worst case versus best case. Our previous studies have shown that remodeling is associated with a greater risk of failure, particularly for patients who have Marfan syndrome and tricuspid aortic valves. ${ }^{5,14}$ In addition, failure risk is higher for patients who have bicuspid versus tricuspid aortic valves. ${ }^{5,8}$ This finding was also reported by David's group in Toronto.

The obvious question, based on analysis of these data, is whether our use of mechanical composite grafts should have abated as quickly as it did. Clearly, early mortality is low, as we and others have reported, ${ }^{6,11}$ as is risk of late death and reoperation. This population is similar to the more-current valve-preservation population, ${ }^{5}$ with the exception of those patients who have aortic valve stenosis and receive mechanical composite grafts. A few patients with unicuspid or bicuspid valves may undergo repair despite stenosis, because partial fusions can be resected. Nevertheless, our data show that postoperative mechanical composite graft gradients are higher, and left ventricular remodeling is less complete, although we cannot determine whether these differences will result over time in more heart failure from either diastolic or systolic heart dysfunction.
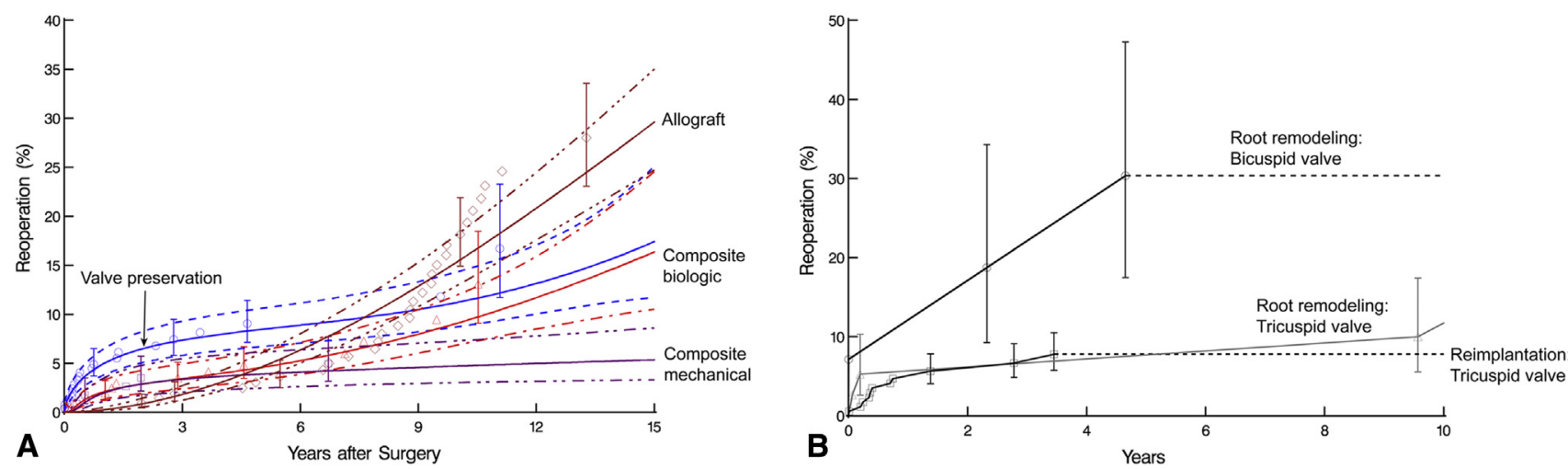

FIGURE 3. Probability of first aortic or aortic valve-related reoperation. Solid lines represent parametric estimates enclosed within $68 \%$ confidence bands equivalent to \pm 1 SE. Symbols are nonparametric Kaplan-Meier estimates with $68 \%$ confidence band. A, Stratified by 4 surgical strategies. B, Stratified by root remodeling for bicuspid valves versus reimplantation or remodeling for tricuspid aortic valves. 
TABLE 4. Propensity-score risk-adjusted $P$ values comparing aortic root procedure groups for risk of reoperation

\begin{tabular}{lccc}
\hline \multicolumn{1}{c}{ Factor } & \multicolumn{2}{c}{ Composite graft } & \\
\cline { 2 - 3 } & Biologic & Mechanical & Allograft \\
\hline Early phase & & & \\
Valve preservation & $.4^{*}$ & $.05^{*}$ & $.02^{*}$ \\
Composite biologic & & $.3^{*}$ & $.05^{*}$ \\
Composite mechanical & & & $.3 *$ \\
Late phase & & & \\
Valve preservation & $.02 \dagger$ & $.7^{*}$ & $.008 \dagger$ \\
Composite biologic & & $.02^{*}$ & $.7 \dagger$ \\
Composite mechanical & & & $.009 \dagger$ \\
\hline
\end{tabular}

*Lower risk of reoperation. $\dagger$ Higher risk of reoperation.

The other obvious issues are the mechanical valve-related complications of embolism, endocarditis, pannus tissue ingrowth, hemorrhage from anticoagulation, high-intensity transient signals that may be related to nitrogen bubbles in solution, and late neurocognitive deficits. ${ }^{5,6,9}$ These valve-related risks are lower with valve preservation, but the downside of this approach is an early risk of reoperation in patients who have bicuspid valves. Nevertheless, risk of death for reoperations was low for all patients, including those with endocarditis on prior root replacements; a similar low risk was previously reported by Lytle and colleagues. ${ }^{18}$

At present, this study cannot settle the debate about whether increased use of biologic composite grafts, which comprise approximately $30 \%$ of our most recent procedures (Figure 1), is justified on the basis of potential transcatheter valve-in-valve replacement. Clearly, patients with aortic valve stenosis and the elderly are good candidates. Nevertheless, younger patients are increasingly requesting biologic valves in hopes of later receiving a valve-in-valve procedure; long-term surveillance will be needed to evaluate whether this choice is justified.

Additional drawbacks are less left ventricular remodeling, increasing gradients, valve-related complications, and risk of reoperation. The same applies to allograft root replacement, although as a rule, these patients are not good candidates for

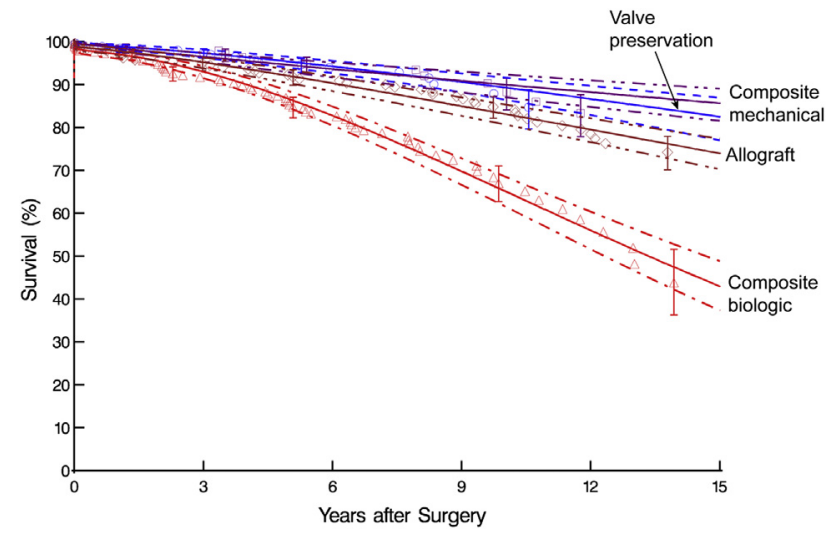

FIGURE 4. Survival stratified by 4 surgical strategies. Format is as in Figure $3, A$. percutaneous valve-in-valve procedures because of the risk of coronary artery occlusion. ${ }^{19}$ Thus, with the exception of endocarditis, we continue to advocate for valve preservation and biologic composite grafts as better alternatives to allografts. Furthermore, late allograft dilatation poses a substantial risk when allograft root replacement is used in patients who have aneurysmal disease, and late calcification makes reoperation more challenging.

\section{Limitations}

This is not a randomized study, but rather a comparison of outcomes of root procedures based on a selection of procedures deemed appropriate by surgeons, in discussion with their patients at a single institution. Clearly, the underlying pathology and time period also influenced the type of procedure chosen, but long-term appropriateness can be measured only with the passage of time. However, the temporal and procedural heterogeneity allowed us to evaluate the appropriateness of each approach. In addition, we did not fully evaluate valve-related complications, although these seem to be lower for valve preservation and allograft root replacement.

\section{Clinical Implications}

Based on our current knowledge, for patients who have aneurysmal disease of the aortic root and ascending aorta, we recommend the following root procedure in combination with ascending aorta replacement, as shown by our treatment algorithm (Figure 5). (1) Valve preservation by modified reimplantation is preferred for tricuspid aortic valves without aortic valve stenosis (to November 2015, we have performed 541 modified reimplantation procedures). (2) Valve preservation by remodeling is the best approach for bicuspid nonstenotic valves, particularly those with larger annuli, but results of modified reimplantation need to be further evaluated. (3) Excellent results can be achieved with composite graft replacement with a mechanical valve for young patients who have stenotic aortic valves; and composite graft replacement with a biologic valve is a reasonable option in elderly patients who have aortic valve stenosis. (4) Allograft root and ascending aorta replacement with coronary reimplantation is best reserved for patients who have endocarditis, and perhaps for elderly patients with a small aortic annulus.

\section{Conflict of Interest Statement}

Dr Svensson is an unpaid member of the executive committee for PARTNER trials I and II, Chairman of the PARTNER Publication Committee, and an unpaid member of the executive committee of the COMMENCE trial, sponsored by Edwards Lifesciences (Irvine, Calif). Dr Roselli has financial relationships with Medtronic, Sorin, St Jude, Edwards Lifesciences, and Terumo. Dr Gillinov is a consultant for Edwards Lifesciences, Medtronic, On-X, Abbott Vascular, and Tendyne, receives 


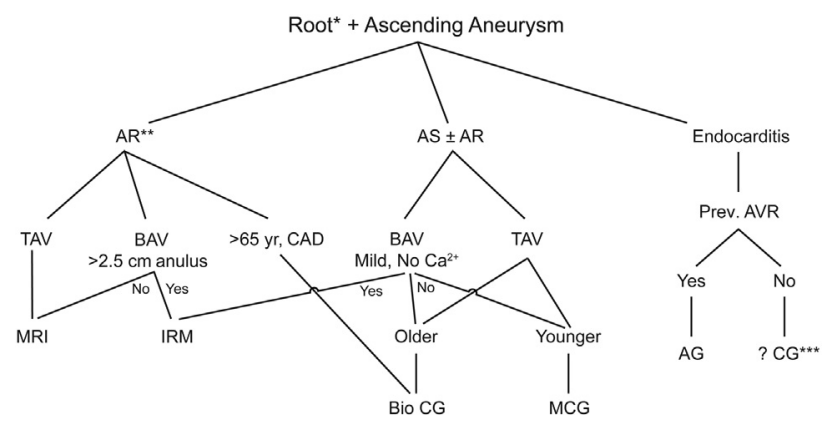

* The Ross procedure should not be used for root aneurysms. ** No $\mathrm{Ca}^{2+}$ or large fenestration. Allografts are prone to dilation.

FIGURE 5. Current Cleveland Clinic treatment algorithm for combined root and ascending aortic aneurysms. $A R$, Aortic regurgitation; $A S$, aortic valve stenosis; $T A V$, tricuspid aortic valve; $B A V$, bicuspid aortic valve; $C A D$, coronary artery disease; $\mathrm{Ca}^{2+}$, calcification; Prev., previous; $\mathrm{AVR}$, aortic valve replacement; $M R I$, modified root-preserving reimplantation ${ }^{10}$; $I R M$, inclusion type of remodeling ${ }^{6,8} ; A G$, allograft; ?CG, possibly composite valve graft, ${ }^{12}$ depending on root abscess presence or active infection; Bio, biologic ${ }^{12}$; $M C G$, mechanical composite graft. ${ }^{12}$

research support from and is a speaker for St Jude, and holds equity in Clear Catheter. Dr Navia is a consultant for Edwards Lifesciences, St Jude Medical, and MAQUET, and is a member of the Scientific Board of NaviGate Cardiac Structures. Dr Smedira is a consultant for Medtronic and Edwards Lifesciences. Dr Sabik discloses financial relationships with Medtronic, Sorin, Edwards Lifesciences, and Abbott. All other authors have nothing to disclose with regard to commercial support.

You can watch a Webcast of this AATS meeting presentation by going to: http://webcast.aats.org/2015/Video/ Tuesday/04-28-15_4E_0845_Svensson.mp4.

The nonlinear mixed-effects models were developed with support from National Institutes of Health grant 1R01HL10355201A1: Ancillary Comparative Effectiveness of Atrial Fibrillation Ablation Surgery.

\section{References}

1. Bentall $\mathrm{H}$, De Bono A. A technique for complete replacement of the ascending aorta. Thorax. 1968;23:338-9.

2. De Paulis R, Scaffa R, Maselli D, Weltert L, Salica A, Bellisario A. Valsalva graft in the Bentall procedure: from mechanical valve to the BioValsalva, world's first biological aortic conduit. Surg Technol Int. 2008;17:216-21.

3. Gulbins H, Kreuzer E, Uhlig A, Reichart B. Homografts in patients with combined disease of the aortic valve and the ascending aorta: an alternative to the classical Bentall procedure. J Heart Valve Dis. 2001;10:650-5.

4. David TE, Feindel CM, David CM, Manlhiot C. A quarter of a century of experience with aortic valve-sparing operations. J Thorac Cardiovasc Surg. 2014;148:872-9; discussion 9-80.

5. Svensson LG, Batizy LH, Blackstone EH, Gillinov AM, Moon MC, D'Agostino RS, et al. Results of matching valve and root repair to aortic valve and root pathology. J Thorac Cardiovasc Surg. 2011;142:1491-8.

6. Svensson LG, Longoria J, Kimmel WA, Nadolny E. Management of aortic valve disease during aortic surgery. Ann Thorac Surg. 2000;69:778-83; discussion 83-4.
7. Blehm A, Schurr P, Sorokin VA, Zianikal I, Kamiya H, Albert A, et al. Comparison of different surgical techniques in 112 consecutive patients with aortic root operations: When should the valve be spared? J Heart Valve Dis. 2014:23:9-16

8. Svensson LG, Al Kindi AH, Vivacqua A, Pettersson GB, Gillinov AM, Mihaljevic T, et al. Long-term durability of bicuspid aortic valve repair. Ann Thorac Surg. 2014;97:1539-47; discussion 48.

9. Svensson LG, Crawford ES, Hess KR, Coselli JS, Safi HJ. Composite valve graft replacement of the proximal aorta: comparison of techniques in 348 patients. Ann Thorac Surg. 1992;54:427-37; discussion 38-9.

10. Svensson LG. Sizing for modified David's reimplantation procedure. Ann Thorac Surg. 2003;76:1751-3.

11. Nakahira A, Shibata T, Sasaki Y, Hirai H, Hattori K, Hosono M, et al. Outcome after the modified Bentall technique with a long interposed graft to the left coronary artery. Ann Thorac Surg. 2009;87:109-15.

12. Svensson LG. Approach for insertion of aortic composite valve grafts. Ann Thorac Surg. 1992;54:376-8.

13. Beach JM, Mihaljevic T, Rajeswaran J, Marwick T, Edwards ST, Nowicki ER, et al. Ventricular hypertrophy and left atrial dilatation persist and are associated with reduced survival after valve replacement for aortic stenosis. $J$ Thorac Cardiovasc Surg. 2014;147:362-9.

14. Svensson LG, Blackstone EH, Feng J, de Oliveira D, Gillinov AM, Thamilarasan M, et al. Are Marfan syndrome and marfanoid patients distinguishable on long-term follow-up? Ann Thorac Surg. 2007;83:1067-74

15. Svensson LG, Cooper M, Batizy LH, Nowicki ER. Simplified David reimplantation with reduction of anular size and creation of artificial sinuses. Ann Thorac Surg. 2010;89:1443-7.

16. Miller DC. Valve-sparing aortic root replacement: current state of the art and where are we headed? Ann Thorac Surg. 2007;83:S736-9; discussion S785-90.

17. Kvitting JP, Kari FA, Fischbein MP, Liang DH, Beraud AS, Stephens EH, et al David valve-sparing aortic root replacement: equivalent mid-term outcome for different valve types with or without connective tissue disorder. $J$ Thorac Cardiovasc Surg. 2013;145:117-26. 27 e1-5; discussion 26-7.

18. Lytle BW, Sabik JF, Blackstone EH, Svensson LG, Pettersson GB, Cosgrove DM III. Reoperative cryopreserved root and ascending aorta replacement for acute aortic prosthetic valve endocarditis. Ann Thorac Surg. 2002;74:S1754-7; discussion S1792-9.

19. Tuzcu EM, Kapadia SR, Svensson LG. Valve in valve: another milestone for transcatheter valve therapy. Circulation. 2012;126:2280-2.

Key Words: aorta, root, aortic valve, root sparing, valve preservation

\section{Discussion}

Dr T. David (Toronto, Canada). Thank you for inviting me to discuss this paper, and I have to congratulate Dr Svensson and colleagues from the Cleveland Clinic on their ability to do 957 aortic root replacements with an operative mortality of .73\%, which is something I cannot do. So I am envious. I had the advantage of having read the article, at least the first draft, so I am going to add a bit more information than we heard in the presentation, to make my comments more appropriate.

First of all, I am a bit surprised by the number of patients. During a 16-year interval, at an institution as large as the Cleveland Clinic, you operated on only 957 aortic roots. If you divide that by 16 years, that means 60 patients per year. The Toronto program is a fraction of the size of the Cleveland Clinic, and we do more than that. You must have selected these patients, or there must be exclusion criteria to enter into this study. Would you tell us the criteria selection?

Dr Svensson. As I mentioned in my presentation, we excluded the patients who did not have their ascending aorta done at the same time. So, for example, if you look at the 
allograft population as of December 2013, we had operated on 1760 allografts, but those were often for just the valve and did not involve the ascending aorta. So those patients were excluded, unless their ascending aorta was replaced for aneurysmal disease. We wanted to gather a series of patients in whom either of the operations was feasible, for fair comparison.

Similarly, for the David reimplantations, we have done 505. Those have been more concentrated in the last few years. The study ended in 2011, as far as the patients we included for long-term follow-up reasons. We have considerably decreased the number of mechanical composite valve grafts we do, but as you saw, our biologic composites increased for the last few years. That increase is not entirely reflected in our current practice, in which biologic composites have declined, because we cut off the data in 2011 so we could get long-term survival in order to compare the procedures.

Dr David. So you excluded dissections, and excluded the endocarditis cases?

Dr Svensson. Acute dissections and endocarditis, and patients who did not have the ascending aorta concurrently done. However, one quarter had arch replacement also.

Dr David. And patients who did not have replaced ascending aortas?

Dr Svensson. They were not included, as I mentioned.

Dr David. I am starting to feel better now. So, a mortality of $0.7 \%$ in a highly select group, I think, is reasonable; actually, it should be expected. In the manuscript, you indicated that the diameter of the ascending aorta and/or the aortic root was under $50 \mathrm{~mm}$, actually 46 and $47 \mathrm{~mm}$.

Dr Svensson. Yes, if including circulatory arrest and arch surgery is a lower risk?

Dr David. What are your criteria to replace an ascending aorta and an aortic root if the mean diameter is 46 or $47 \mathrm{~mm}$ ?

Dr Svensson. That is a very good question. Our cutoff is usually $5 \mathrm{~cm}$, but we additionally use the cross-sectional area to the height ratio, and if it is $>10 \mathrm{~cm}$, we consider that to be an indication for operation. So, for example, in the series, a number of patients had Turner syndrome. Quite a lot of patients had descending dissections or ascending dissections that we felt would be good candidates, potentially, for a reimplantation operation.

The other thing I have been doing (and I am not ready to report on this yet; we will see how it holds up) is modified reimplantations for patients with severe aortic regurgitation. Reimplantation gives you, I think, considerable control of the cusps, and we have had some remarkable successes. In patients with $\geq 4$ aortic regurgitation, we do a reimplantation. Then you can work on the cusps, and you get really good results.

Dr David. Another comment is that the 4 groups are not comparable in age or pathology. If you have a patient with aortic valve stenosis, you cannot do an aortic valve-sparing operation, and that patient is not comparable to a patient who has aortic insufficiency or an aortic root aneurysm.
Therefore, comparison of longitudinal outcomes is meaningless because they are different patients. Second, if the patients are different, with some patients who had aortic stenosis and insufficiency or simple aortic root aneurysm, then doing regression in the whole group that had a left ventricular mass is inappropriate, and so are the gradients.

Dr Svensson. Well, I take your point, but we tried to balance these groups as much as possible by looking at long-term outcomes. I fully understand that there are going to be different degrees of regression if there is aortic valve stenosis versus aortic valve regurgitation. But if you take total mass, as we did, the patients, although they may have severe aortic regurgitation and a big ventricle, if you look at the total mass, it is usually higher than that for a person who has a normal ventricle. I did, however, notice that you have a poster with a similar comparison.

Dr David. Again, you did not show it in your slides, but I had the advantage of reading the manuscript, and $75 \%$ of the patients had echocardiography, although the time interval from the operation was not given. So you have to eliminate one fourth of the patients. However, at 10 years, $75 \%$ were free from severe or moderately severe aortic insufficiency.

That is not a very good operation for sparing a valve, because at 10 years, $25 \%$ had moderately severe or severe aortic insufficiency. Why did you shift from a mechanical to a valve-sparing approach, given these results?

Dr Svensson. Well, we did not know what the results were going to be 10 years later, obviously, but if I could predict the future that way, I probably would be working in the stock market or something like that. But I think the important point here is that we did not know what the results were going to be over the long term. I take your point fully that aortic valve regurgitation was higher with the valve-preserving operations. It is particularly the remodeling group of patients that we showed to have more regurgitation. And as you and others have shown, remodeling does not generally hold up as well as a reimplantation operation. So one has to use that operation with caution. Although it seems to be easier, the long-term data are not as supportive.

I would say in deference to your studies, versus ours, that our echos are mainly of patients who are referred back to us, because $80 \%$ of our patients are from outside our area. So they come back because they have a problem. In your patients, you have longitudinal follow-up that your cardiologists do for you on a regular basis, and you have access to those data. We, unfortunately, do not. I wish we did.

Dr David. Finally, in 2006, Dr Smedira presented a paper to this association, comparing allografts to a Perimount valve, and he showed that even in patients aged $<50$ years, freedom from re-explantation was not different at 10 and 15 years. Should we abandon homografts entirely, as opposed to replacing the aortic root with them the way you showed?

Dr Svensson. Well, as you saw, I showed the similar durability of allografts and pericardial valves. As you saw 
on our yellow curve of risk of operation of allografts versus the other root procedures, the failure rates were higher, so we have essentially abandoned using allografts in patients who do not have endocarditis. Although we have a huge amount of experience with allografts, we have abandoned their use in patients with root and ascending aneurysm alone. So I think you are right in that one should use a biologic pericardial valve, given the option. Certainly the reoperation is safer (although in our hands, for 370 allograft reoperations, mortality was $1.2 \%$ ). That is why I think you saw on the slide that there was a big increase in pericardial valves with composite roots, particularly with flared grafts.

Dr David. Again, I would like to thank the association for the privilege of discussing the paper.

Dr Svensson. Thank you for your comments, Dr David.

Dr D. Cameron (Baltimore, $M d$ ). Lars, thank you very much. I enjoyed this presentation, and it is a remarkable series.

Two short questions: First, the Ross procedure is an aortic root replacement, but it was not included in this series. What is the role of the Ross at your institution, and where does it fit, in the spectrum of these procedures? Second, in the bicuspid aortic valve group, many of them failed after valve-sparing, and they all had remodeling. Are they failing because they should have had reimplantation, or because of the limits of valve repair in the bicuspid group?

Dr Svensson. Those are both excellent questions, Duke, and I appreciate your insights. As far as the Ross procedures, we excluded them, because first of all, we do not believe that the Ross is a good procedure in a patient who has aneurysmal disease of the aorta and the ascending aorta, because we generally do not do a Ross plus an ascending tube graft, or for that matter, a Ross and an ascending aorta plus arch elephant trunk. So those were not included for that reason.

As far as indications for doing a Ross, we still believe that there is a role for a Ross in young aortic valve stenosis patients who do not have aneurysmal disease. I think with aneurysmal disease, one should use it with great caution, and similarly with patients who have aortic valve regurgitation. Concerning the remodeling, is it because the valves are not holding up, or is it because of the procedure? I think it is a mixture of both. Certainly, in some of those reoperations, over time, the cusps had stretched and prolapsed. So although we stabilize the aortic root, we do it internally. I used to do a polytetrafluoroethylene band (see footnote*), but I had some patients who developed heart block with that, so I have abandoned using external fixation and now do it internally. But despite that, over time, those cusps tend to prolapse, or obviously, they develop aortic valve stenosis.

* Gore-Tex, registered trademark of W. L. Gore \& Associates, Inc, Flagstaff, Ariz.
Is the reimplantation operation a better option for bicuspid valves? I think it is a very good operation if you use a big tube graft. You need to use something like a 34- or a 38-mm graft size. Clearly, you have to be very careful in that group of patients, as far as not causing prolapse, if they have very long cusps. The graft must be wide enough to accommodate the cusps. I do not think we have the ideal operation for the root aneurysms associated with bicuspid valves. I think that is still a work in progress.

\section{Dr Moon. Dr David?}

Dr David. I agree. I think Gebrine El Khoury showed that incompetent bicuspid aortic valves are the valves with the largest aortic annulus. Believe it or not, I have seen one with an annular diameter of $50 \mathrm{~mm}$. Obviously, I am biased, but reimplantation is the only operation that can provide a satisfactory result after repairing a bicuspid aortic valve. You have to reduce the diameter of the aortoventricular junction by placing it into a Dacron cylinder.

Dr T.B. Reece (Denver, Colo). I just had a question about what your philosophy is on the biologic roots now-in what age patient are you starting to put them in, versus mechanical? In addition, what are the technical aspects that you alluded to in terms of having a higher rate of coronary implantation, and should we be doing Cabrol's on these patients, or something that raises it even higher than we are able to stretch the coronary button in most patients?

Dr Svensson. That is a good question, Brett. So for biologic valves, we avoid composites in the younger population. I am not keen to do that in somebody aged $<50$ years, and preferably $\geq 65$ years, because these reoperations are potentially more complicated. On the other hand, we have many patients who now have the strategy in their own minds that they want to have a transcatheter aortic valve replacement as the second procedure.

So if you are going to do a biologic composite, I would recommend that you use one of the flared grafts, so that the coronary artery buttons are displaced away from the cusps, and you do not run the risk of occluding them when you do the transcatheter aortic valve replacement. That is one of the reasons we generally avoid using stentless valves, because you do not displace those coronaries as far as you would with a composite biologic valve with a flared root. So that is a critical part of a biologic composite graft. Similarly with allografts, there is some concern about occlusion of the coronaries with a valve-in-valve. So that is basically the way we manage those patients.

\section{Dr Moon. Dr David?}

Dr David. A redone Bentall procedure is not a simple operation, and I do not give young patients bioprosthetic valves unless there is a contraindication to warfarin. The Bentall procedure has been around for 50 years and has been a good operation. We have started to change now, putting Perimount valves in 30-year-old patients. There is no percutaneous aortic valve implantation that is going to 
carry this patient to adult life or old age. I think you tell them to take warfarin and have a mechanical valve, and reserve the operation that Lars mentioned to the elderly, patients who are $\geq 60$ years.

Dr D. Adams (New York, NY). First of all, I take issue with Dr David stating that "the elderly" are 60 years and older, as we all approach that age! I did want to ask Lars-is there an age for a patient at which you stop doing reimplantation or remodeling?

Dr Svensson. That is a very good question, and I guess the answer is, what is the long-term durability of a biologic valve in that population? When we looked at that issue, the biologic valves start failing at about 6 to 7 years. They do not need a reoperation at that point, but usually by 10,12 , or 15 years, they start needing more reoperations.

A lot of my patients have a great affinity for their own valves, and so even the elderly say, "I'd like to keep my own valve, if you can." I think that the important point from this presentation is that we discovered that there is a high risk of endocarditis in the patients who had biologic composites, apart from failure over time. Potentiallyalthough I don't have the data to prove it - I think the stroke rate over time is also greater with a biologic composite than a modified reimplantation.

So I really do not have a hard time point at which I say I do not do a reimplantation. I have certainly done them in 70-yearolds, but I am very careful that the valve is not calcified and that it does not have perforations, because the difference as far as reoperation probably is not that different between a biologic composite and a reimplantation in that age group.

Dr Moon. Dr David-Is that your policy?

Dr David. I am a bit more conservative. A 70- or an 80-year-old with an aortic root aneurysm, by and large does not have annuloaortic ectasia. So either remodeling the sinotubular junction, or remodeling the sinotubular junction and replacing one, two, or three sinuses is a simpler, faster, and safer operation than a reimplantation. Reimplantation is for young patients with aortic root aneurysms associated with genetic syndromes.

Dr Svensson. I perhaps take a bit of issue with that, because I think the potential benefits of reimplantation are greater. A composite biologic valve may take 40 or 45 minutes to put in; you add another 10 or 15 minutes and you can do a reimplantation, and you have an operation that has lower risk of endocarditis and lower risk of stroke. It is still, I think, an operation that you potentially could do a transcatheter aortic valve replacement in, and particularly the way we do it with a Hagar, so you created a nice annulus, and the coronaries are far displaced. We obviously have not had to do a TAVR yet, but I think in the future, that will still be a reasonable operation.

Dr C. Fraser (Houston, Tex). Lars, a very quick question, and congratulations on an outstanding presentation. I wanted to focus just a little bit more on the kind of patients I see-younger patients, young adults, and perhaps even adolescents. I am very impressed at how good an operation the mechanical composite root still is. Of course, you did not present information about long-term anticoagulationrelated complications, but in the era of home international normalized ratio monitoring, are you discouraging young people who come in and say, look, I am just going to take my chances and have a mechanical composite root because the reoperation rate is so low?

Dr Svensson. Dr David, you were invited to go first.

Dr David. We have been doing this for 27 years now, and in tricuspid aortic valve, with associated genetic syndromes, we have no failures. Yes, the first 2 failed; I was learning how to do the operation. But once I passed the learning curve, you are going to see a paper coming out showing 20 -year results in patients with Marfan syndrome. It is a stable operation, aortic valve reimplantation.

Dr Fraser. Dr David, surely you agree that there are patients who present in that age range who are not candidates for a valve-sparing procedure; say, a very bad bicuspid aortic valve that is not repairable.

Dr David. Then a mechanical valve, of course.

Dr Fraser. Is that right, or would you recommend a homegrown composite biologic prosthesis?

Dr Svensson. Chuck, my take on it is that I think the mechanical composite valve graft is an excellent operation. It was interesting that the long-term data looked as good as they did, similar to what I reported for Dr Crawford's patients. We need to do a long-term study just looking at reimplantations for tricuspid valves, versus mechanical composites, in young patients.

I think there are 2 important points about the composites. First, you tie the knots outside the bloodstream, and so maybe the risk of endocarditis is lower, but certainly the risk of stroke over time, versus an isolated aortic valve, is much lower (we showed that in the paper many years ago on Dr Crawford's patients; Vincent Gott showed the same).

To get back to Brett's question about composite valves, mechanical valves-I do not believe in the Cabrol procedure. I think that is a bad operation. There is a high myocardial infarction risk. But the operation that I described many years ago is to sew a tube graft to the left main, bring it up on the right side of the aorta for attachment, and do a button for the right. That is a very durable and good operation, particularly in young patients, particularly with acute dissection or reoperations where you have maybe a slightly greater risk of mobilizing the left main. I would not say it is much, but it makes for a very good operation; you get great hemostasis. It is my "goto" operation for acute dissection in young patients.

Thank you for this interesting discussion, insightful questions, and considered comments. 


\section{APPENDIX E1. STATISTICAL METHODS Balancing Scores}

Because patient characteristics differed among the 4 surgical groups, we used propensity scores (probability of being in 1 of the 4 groups) as balancing scores, to reduce bias before comparing outcomes among groups. ${ }^{\mathrm{E} 1}$ Using preoperative variables (Appendix E2) and generalized logistic regression (PROC LOGISTIC with generalized logit link; SAS Institute, Cary, NC), we identified those variables associated with treatment groups. Having established a parsimonious model, we added other variables that represent factors that might be related to these groups (semisaturated model; see footnote in Appendix E2). Four propensity scores were calculated for each patient by solving the semisaturated model. We then forced 3 scores into models used to compare outcomes of the 4 treatments.

\section{Longitudinal Data Analysis}

Temporal patterns of longitudinal measurements were analyzed using a nonlinear multiphase mixed-effects model, ${ }^{\text {E2 }}$ implemented using PROC NLMIXED (SAS Institute), ordinal longitudinal data were analyzed using a longitudinal cumulative logistic mixed model, and continuous longitudinal measurements were analyzed using mixed-model regression. ${ }^{\mathrm{E} 3}$ Risk-adjusted comparisons were made after including propensity scores in the mixedeffects models.

\section{Analysis of Time-Related Events}

Time-varying instantaneous risk of reoperation and death were assessed nonparametrically by the Kaplan-Meier method and parametrically by a multiphase hazard model. The parametric model was used to resolve several phases of instantaneous risk of explant (hazard function) and to estimate shaping parameters. ${ }^{\mathrm{E} 4}$

\section{Risk Factors for Reoperation}

Multivariable analysis was performed in the hazard function domain. Variables considered in the analysis are listed in Appendix E2. Variable selection, with a $P$-value criterion of .05 for retention in the model, used a computer-intensive machine-learning "bagging" method (bootstrap aggregation) and 500 bootstrap data sets. ${ }^{\mathrm{E}}$ Variables occurring in $\geq 50 \%$ of these models were retained in the final model.

\section{Missing Values}

Several variables examined in multivariable analyses had missing values. We used 5-fold multiple imputation with a Markov chain Monte Carlo technique to impute them (PROC MI; SAS Institute). ${ }^{\mathrm{E} 6}$ In multivariable modeling, for each imputed complete data set, we estimated the regression coefficients and their variance-covariance matrix, then combined the estimates from the 5 models (PROC MIANALYZE; SAS Institute) to yield final regression coefficient estimates, the variance-covariance matrix, and $P$ values.

\section{E-References}

E1. Blackstone EH. Comparing apples and oranges. J Thorac Cardiovasc Surg. 2002; 123:8-15

E2. Rajeswaran J, Blackstone EH. A multiphase non-linear mixed effects model: an application to spirometry after lung transplantation. Stat Meth Med Res. 2014

E3. Diggle PJ, Heagerty PJ, Liang KY, Zeger SL. Analysis of longitudinal data. 2nd ed. New York: Oxford University Press; 2002.

E4. Blackstone EH, Naftel DC, Turner ME Jr. The decomposition of time-varying hazard into phases, each incorporating a separate stream of concomitant information. J Am Stat Assoc. 1986;81:615-24.

E5. Sauerbrei W, Schumacher M. A bootstrap resampling procedure for mode building: application to the Cox regression model. Stat Med. 1992;11 2093-109.

E6. Rubin DB. Multiple imputation fornon-response in surveys. New York: Wiley; 2004. 
APPENDIX E2. Variables considered in multivariable model

\section{Patients}

Demographic

Symptoms

Ventricular dysfunction

Aortic valve pathology

Aortic valve function/size

Aortic valve etiology

Other pathology

Coronary anatomy

Other cardiac comorbidity

Noncardiac comorbidity

Experience

\section{Left ventricular}

Structure

Function

Left atrial

Left atrium

Intraoperative

Procedure

Concomitant procedure

Support
Age $(\mathrm{y}), *$ gender,* race, ${ }^{*}$ weight $(\mathrm{kg})$, height $(\mathrm{cm})$, body surface area $\left(\mathrm{m}^{2}\right),{ }^{*}$ body mass index $\left(\mathrm{kg} / \mathrm{m}^{2}\right)$

New York Heart Association functional class (I-IV)*

Prior myocardial infarction*, graded left ventricular dysfunction (none, mild, moderate, severe)

Aortic valve regurgitation, * aortic valve stenosis, bicuspid,* calcified aorta,* abnormal cuspid*

Mean gradient $(\mathrm{mm} \mathrm{Hg}){ }^{*}$ peak gradient $(\mathrm{mm} \mathrm{Hg})^{*}$

Ascending aortic aneurysm/aortic root dilatation, ${ }^{*}$ degenerative, ${ }^{*}$ rheumatic

Tricuspid valve regurgitation, ${ }^{*}$ mitral valve regurgitation*

Left main trunk disease ( $\%$ stenosis), left anterior descending coronary artery system disease (maximum \% stenosis), ${ }^{*}$ right coronary artery system disease (maximum $\%$ stenosis), ${ }^{*}$ left circumflex coronary artery system disease (maximum \% stenosis)

Ventricular arrhythmia, ${ }^{*}$ heart failure*

History of smoking, ${ }^{*}$ carotid disease, ${ }^{*}$ hypertension, ${ }^{*}$ chronic obstructive pulmonary disease, ${ }^{*}$ treated diabetes, ${ }^{*}$ creatinine $(\mathrm{mg} / \mathrm{dL}),{ }^{*}$ blood urea nitrogen $(\mathrm{mg} / \mathrm{dL}),{ }^{*}$ cholesterol $(\mathrm{mg} / \mathrm{dL}),{ }^{*}$ bilirubin $(\mathrm{mg} / \mathrm{dL}),{ }^{*}$ creatinine clearance, glomerular filtration rate, hematocrit $(\%)^{*}$

Date of operation (years since January 1, 1995)*

Inner diameter in diastole $(\mathrm{cm}), *$ inner diameter in systole $(\mathrm{cm}),{ }^{*}$ diastolic volume $(\mathrm{mL})$, systolic volume $(\mathrm{mL})$, diastolic volume index $\left(\mathrm{mL} / \mathrm{m}^{2}\right)$, systolic volume index $\left(\mathrm{mL} / \mathrm{m}^{2}\right)$, mass $(\mathrm{g})$, mass index $\left(\mathrm{g} / \mathrm{m}^{2}\right)$, ${ }^{*}$ posterior wall thickness $(\mathrm{cm}),{ }^{*}$ septal thickness $(\mathrm{cm})$

Fractional shortening, ejection fraction $(\%), *$ relative wall thickness (wall stress)*

Diameter $(\mathrm{cm})$, volume $(\mathrm{mL})$, volume index $\left(\mathrm{mL} / \mathrm{m}^{2}\right)^{*}$

Valve preservation, composite biologic, composite mechanical, allograft

Atrial fibrillation procedure, internal thoracic artery graft used, congenital heart disease procedure Aortic clamp time ( $\mathrm{min})$, cardiopulmonary bypass time ( $\mathrm{min})$

*Variables included in the balancing score model.

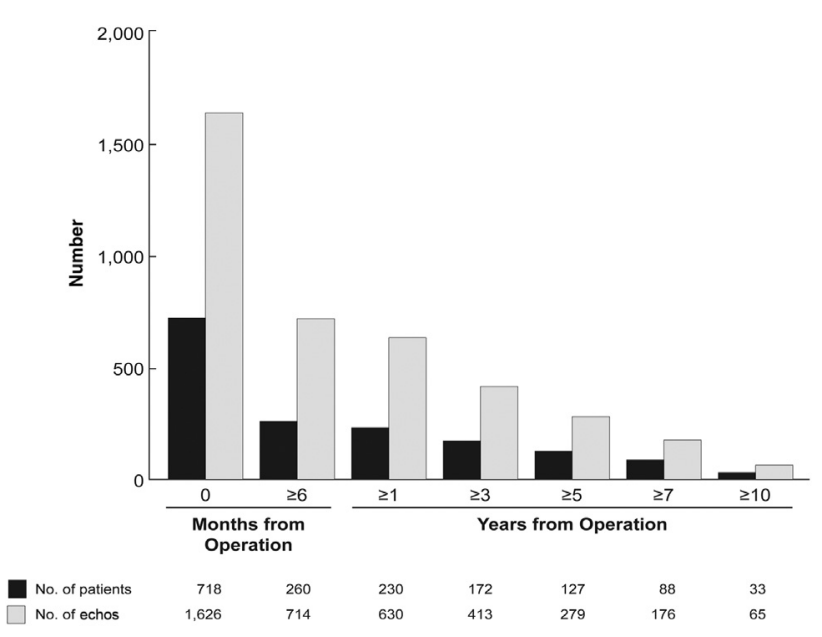

FIGURE E1. Number of patients with echocardiograms available at and beyond various time points, and number of echocardiograms available for analysis. 
TABLE E1. Pre-procedural patient characteristics, stratified by aortic root procedure

\begin{tabular}{|c|c|c|c|c|c|c|c|c|c|}
\hline \multirow[b]{3}{*}{ Characteristic } & \multirow{2}{*}{\multicolumn{2}{|c|}{$\begin{array}{l}\text { Valve preservation } \\
\quad(\mathbf{n}=\mathbf{2 6 1})\end{array}$}} & \multicolumn{4}{|c|}{ Composite graft } & \multirow{2}{*}{\multicolumn{2}{|c|}{$\begin{array}{l}\text { Allograft } \\
(n=243)\end{array}$}} & \multirow[b]{3}{*}{$\begin{array}{c}P \\
\text { value }\end{array}$} \\
\hline & & & \multicolumn{2}{|c|}{$\begin{array}{c}\text { Biologic } \\
(\mathbf{n}=\mathbf{2 9 7})\end{array}$} & \multicolumn{2}{|c|}{$\begin{array}{l}\text { Mechanical } \\
(\mathbf{n}=156)\end{array}$} & & & \\
\hline & $\mathbf{n}^{*}$ & $\begin{array}{l}\text { No. }(\%) \text { or } \\
\text { mean } \pm \text { SD }\end{array}$ & $\mathbf{n}^{*}$ & $\begin{array}{l}\text { No. }(\%) \text { or } \\
\text { mean } \pm \text { SD }\end{array}$ & $\mathbf{n}^{*}$ & $\begin{array}{l}\text { No. }(\%) \text { or } \\
\text { mean } \pm \text { SD }\end{array}$ & $\mathbf{n}^{*}$ & $\begin{array}{l}\text { No. }(\%) \text { or } \\
\text { mean } \pm \text { SD }\end{array}$ & \\
\hline \multicolumn{10}{|l|}{ Demographics } \\
\hline Age (y) & 261 & $48 \pm 14$ & 297 & $66 \pm 11$ & 156 & $47 \pm 11$ & 243 & $53 \pm 14$ & $<.0001$ \\
\hline Male & 261 & $208(80)$ & 297 & $242(81)$ & 156 & $132(85)$ & 243 & $187(77)$ & .16 \\
\hline Height $(\mathrm{cm})$ & 261 & $181 \pm 10$ & 297 & $176 \pm 9.9$ & 156 & $179 \pm 9.6$ & 243 & $175 \pm 10$ & $<.0001$ \\
\hline Body mass index $\left(\mathrm{kg} / \mathrm{m}^{2}\right)$ & 236 & $28 \pm 5.6$ & 271 & $28 \pm 4.9$ & 143 & $29 \pm 5.7$ & 205 & $28 \pm 4.9$ & .3 \\
\hline NYHA functional class & 261 & & 297 & & 156 & & 243 & & $<.0001$ \\
\hline I & & $142(54)$ & & $133(45)$ & & $69(44)$ & & $64(26)$ & \\
\hline II & & $95(36)$ & & $116(39)$ & & $68(44)$ & & $143(59)$ & \\
\hline III & & $23(8.8)$ & & $38(13)$ & & $17(11)$ & & $28(12)$ & \\
\hline IV & & $1(0.38)$ & & $10(3.4)$ & & $2(1.3)$ & & $8(3.3)$ & \\
\hline \multicolumn{10}{|l|}{ Aorta and aortic valve } \\
\hline \multicolumn{10}{|l|}{ Aorta dimensions $(\mathrm{cm})$} \\
\hline Sinus of Valsalva diameter $\dagger$ & 216 & $4.7 \pm 0.67$ & 207 & $4.7 \pm 0.80$ & 102 & $4.7 \pm 1.0$ & 111 & $4.4 \pm 0.95$ & .0009 \\
\hline Mid-ascending diameter $\dagger$ & 237 & $4.2 \pm 0.99$ & 266 & $4.4 \pm 0.94$ & 125 & $4.5 \pm 1.2$ & 207 & $3.9 \pm 0.86$ & $<.0001$ \\
\hline \multicolumn{10}{|l|}{ Aortic valve } \\
\hline \multicolumn{10}{|l|}{ Morphology } \\
\hline Unicuspid & 248 & $0(0)$ & 296 & $4(1.4)$ & 155 & $11(7.1)$ & 243 & $3(1.2)$ & $<.0001$ \\
\hline Bicuspid & 248 & $26(10)$ & 296 & $72(24)$ & 155 & $45(29)$ & 243 & $30(12)$ & $<.0001$ \\
\hline Tricuspid & 248 & $222(90)$ & 296 & $219(74)$ & 155 & $99(64)$ & 243 & $210(86)$ & $<.0001$ \\
\hline Quadricuspid & 248 & $0(0)$ & 296 & $1(0.34)$ & 155 & $0(0)$ & 243 & $0(0)$ & .5 \\
\hline \multicolumn{10}{|l|}{ Pathology } \\
\hline $\begin{array}{l}\text { Aortic root dilatation from } \\
\text { ascending aortic } \\
\text { aneurysm }\end{array}$ & 261 & $250(96)$ & 297 & $162(55)$ & 156 & $108(69)$ & 243 & $117(48)$ & $<.0001$ \\
\hline Degenerative & 261 & $9(3.4)$ & 297 & $126(42)$ & 156 & 45 (29) & 243 & $112(46)$ & $<.0001$ \\
\hline \multicolumn{10}{|l|}{ Hemodynamics } \\
\hline Mean gradient (mm Hg) & 101 & $9.1 \pm 7.3$ & 189 & $20 \pm 14$ & 93 & $21 \pm 15$ & 177 & $27 \pm 20$ & $<.0001$ \\
\hline Peak gradient $(\mathrm{mm} \mathrm{Hg})$ & 105 & $17 \pm 11$ & 191 & $35 \pm 23$ & 93 & $37 \pm 25$ & 178 & $48 \pm 36$ & $<.0001$ \\
\hline \multicolumn{10}{|l|}{ Pathophysiology } \\
\hline Stenosis & 261 & $2(0.77)$ & 297 & $66(22)$ & 156 & $27(17)$ & 243 & $103(42)$ & $<.0001$ \\
\hline Regurgitation & 261 & $180(69)$ & 297 & $261(88)$ & 156 & $141(90)$ & 243 & $201(83)$ & $<.0001$ \\
\hline Regurgitation grade & 260 & & 296 & & 156 & & 243 & & $<.0001$ \\
\hline 0 & & $81(31)$ & & $35(12)$ & & $15(9.6)$ & & $42(17)$ & \\
\hline$\geq 1$ & & $31(12)$ & & $21(7.1)$ & & $6(3.8)$ & & $19(7.8)$ & \\
\hline$\geq 2$ & & $60(23)$ & & $48(16)$ & & $26(17)$ & & $37(15)$ & \\
\hline$\geq 3$ & & $54(21)$ & & $83(28)$ & & $51(33)$ & & $62(26)$ & \\
\hline$\geq 4$ & & $34(13)$ & & $109(37)$ & & $58(37)$ & & $83(34)$ & \\
\hline \multicolumn{10}{|l|}{ Cardiac comorbidities } \\
\hline Mitral valve regurgitation & 261 & $68(26)$ & 297 & $104(35)$ & 156 & $44(28)$ & 243 & $73(30)$ & .13 \\
\hline Tricuspid valve regurgitation & 261 & $48(18)$ & 297 & $74(25)$ & 156 & $30(19)$ & 243 & $44(18)$ & .15 \\
\hline Left ventricular ejection fraction $(\%)$ & 245 & $55 \pm 6.1$ & 280 & $52 \pm 8.8$ & 132 & $53 \pm 7.5$ & 225 & $52 \pm 9.8$ & .0006 \\
\hline Left ventricular mass index $\left(\mathrm{g} / \mathrm{m}^{2}\right)$ & 219 & $119 \pm 38$ & 246 & $150 \pm 54$ & 116 & $143 \pm 48$ & 178 & $146 \pm 44$ & $<.0001$ \\
\hline Left atrial diameter $(\mathrm{cm})$ & 221 & $3.9 \pm 0.76$ & 254 & $4.1 \pm 0.80$ & 117 & $4.0 \pm 0.74$ & 200 & $4.0 \pm 0.75$ & .05 \\
\hline $\begin{array}{l}\text { Right ventricular estimated systolic } \\
\text { pressure }(\mathrm{mm} \mathrm{Hg})\end{array}$ & 173 & $34 \pm 6.6$ & 211 & $37 \pm 9.9$ & 76 & $35 \pm 8.9$ & 150 & $37 \pm 8.8$ & .0001 \\
\hline $\begin{array}{l}\text { No. of diseased coronary artery } \\
\text { systems ( } \geq 50 \% \text { stenosis })\end{array}$ & 229 & & 269 & & 120 & & 155 & & $<.0001$ \\
\hline 0 & & $202(88)$ & & $183(68)$ & & $102(85)$ & & $111(72)$ & \\
\hline 1 & & $15(6.6)$ & & 42 (16) & & $11(9.2)$ & & $26(17)$ & \\
\hline 2 & & $9(3.9)$ & & $25(9.3)$ & & $3(2.5)$ & & $12(7.7)$ & \\
\hline 3 & & $3(1.3)$ & & $19(7.1)$ & & $4(3.3)$ & & $6(3.9)$ & \\
\hline
\end{tabular}




\begin{tabular}{|c|c|c|c|c|c|c|c|c|c|}
\hline \multirow[b]{3}{*}{ Characteristic } & \multirow{2}{*}{\multicolumn{2}{|c|}{$\begin{array}{l}\text { Valve preservation } \\
\qquad(\mathrm{n}=\mathbf{2 6 1}) \\
\end{array}$}} & \multicolumn{4}{|c|}{ Composite graft } & \multirow{2}{*}{\multicolumn{2}{|c|}{$\begin{array}{l}\text { Allograft } \\
(n=243) \\
\end{array}$}} & \multirow[b]{3}{*}{$\begin{array}{c}P \\
\text { value } \\
\end{array}$} \\
\hline & & & \multicolumn{2}{|c|}{$\begin{array}{c}\text { Biologic } \\
(n=297)\end{array}$} & \multicolumn{2}{|c|}{$\begin{array}{c}\text { Mechanical } \\
(\mathbf{n}=156)\end{array}$} & & & \\
\hline & $\mathbf{n}^{*}$ & $\begin{array}{l}\text { No. }(\%) \text { or } \\
\text { mean } \pm \text { SD }\end{array}$ & $\mathbf{n}^{*}$ & $\begin{array}{l}\text { No. }(\%) \text { or } \\
\text { mean } \pm \text { SD }\end{array}$ & $\mathbf{n}^{*}$ & $\begin{array}{l}\text { No. }(\%) \text { or } \\
\text { mean } \pm \text { SD }\end{array}$ & n* & $\begin{array}{l}\text { No. }(\%) \text { or } \\
\text { mean } \pm \text { SD }\end{array}$ & \\
\hline Atrial fibrillation or flutter & 235 & $4(1.7)$ & 270 & $25(9.3)$ & 142 & $5(3.5)$ & 205 & $7(3.4)$ & .0004 \\
\hline Complete heart block or pacer & 235 & $2(0.85)$ & 270 & $3(1.1)$ & 142 & $3(2.1)$ & 205 & $3(1.5)$ & .8 \\
\hline Ventricular arrhythmia & 235 & $12(5.1)$ & 270 & $16(5.9)$ & 142 & $7(4.9)$ & 205 & $16(7.8)$ & .6 \\
\hline Heart failure & 261 & $13(5.0)$ & 297 & $52(18)$ & 156 & $16(10)$ & 243 & $37(15)$ & $<.0001$ \\
\hline \multicolumn{10}{|l|}{ Noncardiac comorbidities } \\
\hline Peripheral arterial disease & 261 & $2(0.77)$ & 297 & $17(5.7)$ & 156 & $2(1.3)$ & 243 & $6(2.5)$ & .002 \\
\hline Carotid disease & 261 & $35(13)$ & 297 & $66(22)$ & 156 & $13(8.3)$ & 243 & $26(11)$ & $<.0001$ \\
\hline Stroke & 261 & $9(3.4)$ & 297 & $16(5.4)$ & 156 & $4(2.6)$ & 243 & $3(1.2)$ & .06 \\
\hline Hypertension & 261 & $152(58)$ & 297 & $208(70)$ & 156 & $81(52)$ & 243 & $127(52)$ & $<.0001$ \\
\hline $\begin{array}{l}\text { Diabetes mellitus, } \\
\text { pharmacologically treated }\end{array}$ & 258 & $6(2.3)$ & 295 & $17(5.8)$ & 155 & $8(5.2)$ & 240 & $9(3.8)$ & .2 \\
\hline COPD & 261 & $27(10)$ & 297 & $33(11)$ & 156 & $7(4.5)$ & 243 & $20(8.2)$ & .10 \\
\hline History of smoking & 259 & $116(45)$ & 294 & $157(53)$ & 156 & $62(40)$ & 240 & $116(48)$ & .03 \\
\hline Creatinine (mg/dL) & 261 & $0.95 \pm 0.20$ & 294 & $1.0 \pm 0.29$ & 156 & $0.99 \pm 0.23$ & 242 & $1.0 \pm 0.62$ & .001 \\
\hline Blood urea nitrogen $(\mathrm{mg} / \mathrm{dL})$ & 261 & $16 \pm 4.5$ & 294 & $19 \pm 6.4$ & 155 & $16 \pm 5.4$ & 242 & $17 \pm 6.3$ & $<.0001$ \\
\hline Bilirubin (mg/dL) & 257 & $0.68 \pm 0.36$ & 281 & $0.77 \pm 0.41$ & 148 & $0.75 \pm 0.42$ & 221 & $0.77 \pm 0.45$ & .002 \\
\hline Total cholesterol (mg/dL) & 202 & $184 \pm 34$ & 234 & $183 \pm 35$ & 124 & $189 \pm 43$ & 170 & $189 \pm 40$ & .4 \\
\hline Triglycerides (mg/dL) & 201 & $150 \pm 99$ & 235 & $123 \pm 72$ & 124 & $160 \pm 125$ & 169 & $144 \pm 126$ & .0007 \\
\hline Hematocrit $(\%)$ & 254 & $42 \pm 4.9$ & 282 & $41 \pm 5.3$ & 150 & $42 \pm 4.8$ & 221 & $40 \pm 4.3$ & .0001 \\
\hline
\end{tabular}

$S D$, Standard deviation; $N Y H A$, New York Heart Association; COPD, chronic obstructive pulmonary disease. *Patients with data available. $\dagger$ These are internal echocardiographic sizes that are expected to be 2 to $3 \mathrm{~mm}$ smaller than true or computed tomography external diameters.

TABLE E2. Label valve size

\begin{tabular}{|c|c|c|c|}
\hline \multirow[b]{2}{*}{ Valve size $(\mathbf{m m})$} & \multicolumn{2}{|c|}{ Composite graft } & \multirow[b]{2}{*}{$\begin{array}{c}\text { Allograft } \\
(n=243) \\
\text { No. }(\%)\end{array}$} \\
\hline & $\begin{array}{c}\text { Biologic } \\
(n=297) \\
\text { No. }(\%)\end{array}$ & $\begin{array}{c}\text { Mechanical } \\
(\mathbf{n}=156) \\
\text { No. }(\%)\end{array}$ & \\
\hline 17 & - & - & $1(0.43)$ \\
\hline 18 & - & - & - \\
\hline 19 & $8(2.7)$ & $1(0.64)$ & $5(2.1)$ \\
\hline 20 & - & - & $10(4.3)$ \\
\hline 21 & $23(7.7)$ & $8(5.1)$ & $65(28)$ \\
\hline 22 & - & - & $68(29)$ \\
\hline 23 & $57(19)$ & $23(15)$ & $21(8.9)$ \\
\hline 24 & - & - & $16(6.8)$ \\
\hline 25 & $127(43)$ & $51(33)$ & $17(7.2)$ \\
\hline 26 & - & - & $11(4.7)$ \\
\hline 27 & $68(23)$ & $44(28)$ & $15(6.4)$ \\
\hline 28 & - & $2(1.3)$ & $3(1.3)$ \\
\hline 29 & $14(4.7)$ & $21(13)$ & $3(1.3)$ \\
\hline 30 & - & - & - \\
\hline 31 & - & $5(3.2)$ & - \\
\hline 32 & - & - & - \\
\hline 33 & - & $1(0.64)$ & - \\
\hline
\end{tabular}

TABLE E3. Propensity-score risk-adjusted comparison of timerelated reoperation among aortic root procedure groups

\begin{tabular}{lcc}
\hline Factor & Coefficient \pm SE & $\boldsymbol{P}$ value \\
\hline $\begin{array}{l}\text { Early hazard phase } \\
\text { Surgical strategy }\end{array}$ & & \\
$\quad$ Valve preservation vs allograft & $3.01 \pm 1.2$ & .02 \\
$\quad$ Composite graft & & \\
$\quad$ Biologic vs allograft & $2.2 \pm 1.2$ & .05 \\
$\quad$ Mechanical vs allograft & $1.4 \pm 1.2$ & .3 \\
Late hazard phase & & \\
$\quad$ Surgical strategy & & \\
$\quad$ Valve preservation vs allograft & $-2.3 \pm 0.86$ & .008 \\
$\quad$ Composite graft & & \\
$\quad$ Biologic vs allograft & $-0.22 \pm 0.63$ & .7 \\
$\quad$ Mechanical vs allograft & $-2.7 \pm 1.1$ & .009 \\
\hline
\end{tabular}

Three propensity scores were incorporated into each hazard phase for risk adjustment. This is the primary analysis for results presented in Table 4, which uses a different reference group. $S E$, Standard error. 